\title{
PERBANDINGAN ALUR DAN LATAR BELAKANG PENGARANG NOVEL 9 MATAHARI KARYA ADENITA DENGAN NOVEL 9 SUMMERS 10 AUTUMNS KARYA IWAN SETYAWAN
}

\author{
Ni Nym. Tresna Dara Laksmi \\ Jurusan Pendidikan Bahasa, Program Pascasarjana, Universitas Pendidikan Ganesha \\ Singaraja, Indonesia \\ e-mail: dara_laksmi@yahoo.com
}

\begin{abstract}
Abstrak
Penelitian deskriptif ini bertujuan untuk (1) membandingkan alur yang terdapat pada novel 9 Matahari karya Adenita dengan novel 9 Summers 10 Autumns karya Iwan Setyawan dan (2) membandingkan latar belakang pengarang yang terdapat pada novel 9 Matahari karya Adenita dengan novel 9 Summers 10 Autumns karya Iwan Setyawan. Subjek penelitian ini adalah novel 9 Matahari karya Adenita dan novel 9 Summers 10 Autumns karya Iwan Setyawan. Objek dalam penelitian ini adalah alur dan latar pengarang novel dalam kajian sastra bandingan. Metode pengumpulan data yang digunakan pada penelitian ini adalah metode dokumentasi. Penelitian ini menggunakan pendekatan kualitatif dengan langkah-langkah: (1) penentuan subjek dan objek penelitian, (2) langkah kerja penelitian (pengumpulan data, pengolahan data, instrumen penelitian, penyajian hasil data), dan (3) penarikan simpulan. Hasil penelitian ini menunjukkan bahwa (1) alur dalam novel 9 Matahari karya Adenita dan novel 9 Summers 10 Autumns karya Iwan Setyawan memiliki tiga persamaan, yaitu tahap pemunculan konflik (generating circumstances), tahap klimaks (climax), dan tahap penyelesaian (denouement) sedangkan perbedaan terletak pada tahap penyituasian (situation) dan tahap peningkatan konflik (rising action). (2) latar belakang pengarang dalam novel 9 Matahari dan novel 9 Summers 10 Autumns memiliki persamaan pada biografi pengarang dan faktor psikologis (proses kreatif) sedangkan perbedaan terletak pada faktor sosiologi. Novel 9 Matahari karya Adenita dan novel 9 Summers 10 Autumns karya Iwan Setyawan sangat inspiratif dan memotivasi dalam menjalankan pendidikan, maka disarankan untuk membaca dan memahami khususnya alur dan latar belakang pengarang.
\end{abstract}

Kata kunci : 9 Matahari, 9 Summers 10 Autumns, Sastra Bandingan

\begin{abstract}
This descriptive study aimed at (1) comparing the plot of 9 Matahari novel by Adenita with 9 Summers 10 Autums by Iwan Setiawan, as well as (2) comparing the writers' background of 9 Matahari novel by Adenita with 9 Summers 10 Autums by Iwan Setiawan. The subject of the study was 9 Matahari Novel by Adenita and 9 Summers 10 Autums by Iwan Setiawan. The object of the study was the plot and the novel writers' background in a comparative literature review. Documentation method was used to collect the research data. This study was a qualitative study with the following procedures: (1) determining the subject and the object of the study, (2) research procedures (data collection, data processing, research instrument, presentation of the result), and (3) drawing conclusion. The result of the study was (1) the plot of 9 Matahari novel by Adenita and 9 Summers 10 Autumn by Iwan Setiawan has three similarities. It is in circumstances generation, climax, and denouement. Meanwhile, the differences are in the situation and action rising. (2) the writer's background of the two novels namely, 9 Matahari and 9 Summers 10 Autums have some similarities which can be seen from the biography of the writer and the psychological factors (creative process) while the difference is in the sociological factor. 9 Matahari novel by Adenita and 9 Summers 10 Autumns by Iwan Setiawan are very inspiring and motivating in education, therefore it is suggested to read and comprehend the plot and writers background.
\end{abstract}

Keywords : 9 Matahari, 9 Summers 10 Autumns, Comparative Literature 


\section{PENDAHULUAN}

Karya sastra adalah bentuk kreativitas dalam bahasa yang berisi sederetan pengalaman batin dan imajinasi yang berasal dari penghayatan atas realitas dan non realitas sastrawannya. Karya sastra sebagai suatu cerita rekaan pada hakikatnya adalah suatu struktur yang terefleksi dalam suatu teks sastra. Struktur tersebut dibina oleh unsurunsur karya sastra. Unsur-unsur yang membangun karya sastra dari dalam disebut dengan unsur instrinsik, sedangkan unsurunsur dari luar yang melatarbelakangi penciptaan karya sastra disebut dengan unsur ekstrinsik. Menurut Istiqomah (2014) Karya sastra pada hakekatnya adalah pengejawantahan kehidupan, hasil pengamaan sastrawan atas kehidupan sekitarnya. Pengarang dalam menciptakan karya sastra didasarkan pada pengalaman yang telah diperolehnya dari realitas kehidupan di masyarakat yang terjadi pada peran tokoh di dunia nyata dan dituangkan ke dalam bentuk karya sastra. Menurut Yanti (2015) Karya sastra merupakan hasil karya manusia dengan mendayungkan imajinasi yang terdapat dalam diri pengarangnya. Keberadaan karya sastra dalam kehidupan manusia dapat mengisi "kedahagaan jiwa" karena membaca karya sastra bukan saja memberikan hiburan, tetapi dapat memberikan pencerahan jiwa. Dengan kata lain, karya sastra dapat memberikan hiburan dan manfaat. Menurut Hermawan (2015) Sebuah karya sastra merupakan proses kreatif seorang pengarang terhadap realitas kehidupan sosialnya. Suatu karya sastra dapat dikatakan baik apabila karya sastra tersebut dapat mencerminkan situasi zaman dan kondisi yang berlaku dalam masyarakatnya.

Dalam unsur intrinsik, alur merupakan kerangka dasar yang amat penting. Menurut Marjorie Boulton (dalam Sudjiman, 1992; 29) mengibaratkan alur sebagai kerangka di dalam tubuh manusia. Tanpa kerangka, tubuh tidak dapat berdiri. Alur mengatur bagaimana tindakan-tindakan harus bertalian satu sama lain, dan bagaimana suatu peristiwa mempunyai hubungan dengan peristiwa lain. Alur sebagai peristiwa-peristiwa yang ditampilkan dalam cerita yang tidak bersifat sederhana, karena pengarang menyusun peristiwa-peristiwa itu berdasarkan kaitan sebab akibat.

Selain alur, latar belakang pengarang bagian dari unsur ekstrinsik juga memiliki peranan penting dalam menciptakan sebuah karya sastra. Latar belakang pengarang adalah faktor-faktor dari dalam pengarang itu sendiri yang memengaruhi atau memotivasi pengarang dalam menulis sebuah karya sastra. Latar belakang pengarang ini menyangkut asal daerah atau suku bangsa, jenis kelamin, pendidikan, pekerjaan, agama, dan ideologi pengarang. Unsur-unsur ini sedikit banyak akan berpengaruh pada isi karya sastra. Salah satu karya sastra yang berpengaruh pada latar belakang pengarang yaitu novel. Menurut Akbar dkk (2013) Novel adalah cerita fiksi yang mengangkat permasalahan yang kompleks tentang kehidupan dan tersusun atas unsur intrinsik dan ekstrinsik yang padu dan saling terikat dalam mengungkapkan setiap jalinan peristiwa yang diceritakan. Menurut Azizah dan Setiana (2016) Novel adalah sebuah karya fiksi prosa yang ditulis secara naratif; biasanya dalam bentuk cerita. Penulis novel disebut novelis. Kata novel berasal dari bahasa Italia novella yang berarti "sebuah kisah atau sepotong berita". Novel lebih panjang (setidaknya 40.000 kata) dan lebih kompleks dari cerpen, dan tidak dibatasi keterbatasan struktural dan metrikal sandiwara atau sajak. Umumnya sebuah novel bercerita tentang tokoh-tokoh dan perilaku mereka dalam kehidupan seharihari.

Sebagai salah satu produk karya sastra, novel memegang peranan penting dalam memberikan berbagai kemungkinan dalam menyikapi kehidupan. Novel adalah karangan prosa yang panjang mengandung rangkaian cerita kehidupan seseorang dengan orang disekelilingnya, menonjolkan watak dan sifat setiap pelaku. Selain itu, novel juga merupakan hasil karya sastra yang di dalamnya mengungkapkan masalah-masalah yang terdapat dalam kehidupan, baik yang berkaitan dengan nilai-nilai sosial, filsafat, moral, toleransi, religius, dan sebagainya. Novel salah satu media termudah yang bisa menjangkau semua orang. Dengan novel, seseorang bisa menyampaikan nilai-nilai tanpa kesan menggurui. Jika membaca sebuah novel, seseorang dapat bercerita dan mengembangkan imajinasinya secara bebas.

Perkembangan novel di Indonesia dari tahun ke tahun terus meningkat, begitu juga dengan permasalahan novelnya. Novel 9 Matahari karya Adenita dengan novel 9 Summers 10 Autumns karya Iwan Setyawan menyajikan permasalahan yang sangat menarik, seperti kehidupan seseorang yang penuh perjuangan. Novel ini dibandingkan karena kedua novel ini merupakan best-seller. Selain itu, kedua novel ini bertema pendidikan serta keduanya menceritakan tentang 
perjuangan seorang mengejar pendidikan meskipun dari keluarga yang berkecukupan. Cerita kedua novel ini memiliki banyak hal positif dan mendidik yang sengaja disisipkan oleh pengarang melalui kisah-kisahnya, seperti keadaan ekonomi keluarga yang berkecukupan tidak mematahkan semangat tokoh Matari Anas dalam novel 9 Matahari karya Adenita dan tokoh Aku dalam novel 9 Summers 10 Autumns karya Iwan Setyawan untuk mencapai pendidikan sarjana serta kesuksesan. Cerita kedua novel ini juga menyadarkan pembaca bahwa pendidikan itu penting dalam kehidupan, karena membekali diri dengan ilmu dapat memudahkan kita menjalani kehidupan yang baik dan layak. Selain itu, kedua novel ini menginspirasi orang yang memiliki masalah ekonomi dalam menjalankan pendidikan agar semangat, pantang menyerah, dan kerja keras untuk dapat merubah hidupnya menjadi lebih baik.

\section{METODE}

Penelitian ini menggunakan rancangan penelitian deskriptif kualitiatif. Deskriptif kualitatif digunakan untuk memperoleh gambaran yang jelas, objek, dan cermat terhadap fenomena-fenomena masyarakat tertentu. Wendra (2014: 53) menyatakan bahwa subjek penelitian adalah benda, hal atau orang, tempat variabel melekat, dan yang dipermasalahkan dalam penelitian. Subjek dalam penelitian ini adalah novel 9 Matahari karya Adenita dan novel 9 Summers 10 Autumns karya Iwan Setyawan. Sementara itu, objek penelitian merupakan pokok persoalan yang hendak diteliti untuk mendapatkan data secara lebih terarah. Objek dalam penelitian ini adalah alur dan latar pengarang novel dalam kajian sastra bandingan. Penelitian ini menggunakan langkah-langkah kerja yaitu pengumpulan data, pengolahan data, instrumen penelitian, penyajian hasil analisis data, dan penarikan kesimpulan. Metode pengumpulan data penulis lakukan dengan menggunakan metode dokumentasi. Metode dokumentasi digunakan untuk memperoleh data yang bersumber pada tulisan, seperti buku, majalah, dokumen, peraturan-peraturan, dan sebagainya (Arikunto, 2003: 158). Instrumen penelitian adalah alat yang sifatnya lebih teknis dan operasional untuk memperoleh data. Sesuai dengan metode yang digunakan, instrumen dalam penelitian ini adalah kartu data. Saat melakukan pengumpulan data, hasilnya akan dicatat dalam kartu data.
Dalam penyajian hasil analisis data ini, langkah terpenting untuk mendapatkan jawaban dari masalah yang ingin dipecahkan. Data yang didapat akan dihubungkan dengan teori-teori yang relevan yang nantinya akan menjawab permasalahan yang ingin dipecahkan. Penelitian ini menggunakan analisis deskriptif kualitatif. Metode analisis deskriptif kualitatif artinya jenis penelitian yang datanya dinyatakan dalam bentuk verbal dan dianalisis tanpa menggunakan metode statistik (Suandi, 2008: 7). Dengan metode analisis deskriptif kualitatif, langkah-langkah yang dilakukan dalam tahap pemrosesan ini, yakni reduksi data (data reduction), klasifikasi, penyajian data (data display), dan simpulan (conclusion drawing/verification).

Reduksi data bertujuan untuk mengetahui data yang didapat valid atau tidak valid. Sugiyono (2007: 339) menyatakan bahwa reduksi data adalah proses berpikir sensitif yang memerlukan kecerdasan, keluasan, dan kedalaman wawasan yang tinggi. Mereduksi data berarti merangkum, memilih hal-hal yang pokok, memfokuskan pada hal-hal yang penting, serta mencari tema, dan polanya (Sugiyono, 2007: 338). Jika yang diperoleh valid, data yang dikumpulkan perlu diklarifikasi. Sebaliknya, jika yang diperoleh tidak valid, data tersebut harus dibuang.

Data yang digunakan dalam penelitian ini ada dua macam, yakni data primer dan sekunder. Data primer adalah novel 9 Matahari dan 9 Summers 10 Autumns, sedangkan data sekunder berupa buku-buku teori sastra yang digunakan dalam menganalisis novel 9 Matahari dan 9 Summers 10 Autumns.

Data-data yang sudah diperoleh melalui reduksi data diolah dan dianalisis untuk memperoleh jawaban yang tepat sesuai dengan rumusan masalah. Dalam penyajian data, data-data akan digambarkan secara rinci dan jelas kemudian dihubungkan dengan teoriteori yang relevan yang nantinya akan menjawab permasalahan yang ingin dipecahkan. Penyajian data dilakukan dengan menguraikan hal-hal yang telah direduksi ke dalam bentuk uraian sesuai dengan rumusan masalah.

Penyimpulan harus dapat menjawab semua masalah yang diangkat dalam penelitian tersebut. Penyimpulan penting dilakukan untuk mengetahui keakuratan penelitian. Penyimpulan dilakukan untuk menjawab rumusan masalah sehingga dapat diperoleh informasi mengenai perbandingan alur dan latar belakang pengarang dalam 
novel 9 Matahari karya Adenita dengan novel 9 Summers 10 Autumns karya Iwan Setyawan.

\section{HASIL DAN PEMBAHASAN}

Berdasarkan penelitian yang telah
dilakukan, diperoleh beberapa temuan
berharga. Temuan pertama yaitu
perbandingan alur yang terdapat pada novel 9 Matahari karya Adenita dengan novel 9 Summers 10 Autumns karya Iwan Setyawan. Alur merupakan rentetan atau urutan peristiwa yang memudahkan pembaca memahami cerita dalam fiksi. Alur berkaitan dengan masalah bagaimana peristiwa, tokoh, dan segala sesuatu yang digerakkan, dikisahkan sehingga menjadi sebuah rangkaian cerita yang padu dan menarik. Selain itu, alur juga mengatur berbagai peristiwa dan tokoh itu tampil dalam urutan yang enak, menarik, tetapi juga terjaga kelogisan dan kelancaran ceritanya. Proses terjadinya alur pada dasarnya direncanakan oleh pencerita. Pada umumnya alur bergerak dari serentetan peristiwa menuju ke klimaks dan berakhir pada selesaian. Alur dalam novel 9 Matahari (9M) karya Adenita dan 9 Summers 10 Autumns (9M10A) karya Iwan Setyawan dibedakan menjadi lima bagian, yaitu a) tahap penyituasian (situation), berisi pelukisan dan pengenalan situasi latar dan tokoh-tokoh cerita, b) tahap generating circumstances, yaitu tahap pemunculan konflik, c) tahap peningkatan konflik (rising action), yaitu tahap konflik yang telah muncul pada tahap sebelumnya semakin berkembang dan dikembangkan kadar intensitasnya, d) tahap klimaks (climax), yaitu pertentangan yang terjadi, yang diakui dan atau ditimpakan kepada para tokoh cerita mencapai titik intensitas puncak, dan e) tahap denouement, yaitu tahap penyelesaian, konflik yang telah mencapai klimaks diberi penyelesaian, ketegangan dikendorkan.

\section{Tahap Penyituasian (Situation)}

Tahap pengenalan awal dalam novel 9 Matahari karya Adenita, pengarang langsung mengarah pada kondisi ekonomi keluarga yang kurang mampu membiayai keinginan tokoh (Matari Anas) melanjutkan pendidikan. Tetapi, tokoh (Matari Anas) tidak menyerah dan memiliki ide untuk bisa melanjutkan pendidikan. Berbeda dengan tahap pengenalan awal novel 9 Summers 10 Autumns karya Iwan Setyawan, pengarang memaparkan latar tempat novel dan menceritakan peristiwa penodongan yang dialami tokoh aku (Iwan Setyawan) saat naik kereta untuk menyaksikan kembang api pertamanya.

\section{Tahap Pemunculan Konflik (Generating Circumstances) \\ Tahap ini terjadi ketika pengarang} pada novel 9 Matahari menceritakan tokoh Matari Anas yang tidak lulus UMPTN dan terpaksa mengambil program Diploma 1 (D1). Setelah lulus kuliah D1, Matari Anas mencoba kembali mencari tempat kuliah dengan mengandalkan UMPTN dan ternyata masih gagal. Pada novel 9 Summers 10 Autumns hampir sama dengan novel 9 Matahari yang menceritakan kegagalan dalam UMPTN. Dalam novel 9 Summers 10 Autumns memaparkan Mbak Isa tidak lolos UMPTN dan harus menunggu kesempatan mendaftar lagi tahun depan. Sementara dalam tahun itu pula Mbak Inan akan lulus SMA. Orangtua mereka tidak mungkin bisa membiayai dua anak kuliah, Mbak Isa akhirnya memberikan kesempatan kuliah pada Mbak Inan.

\section{Tahap Peningkatan Konflik (Rising Action)}

Tahap ini merupakan berkembangnya sebuah konflik, ketika pengarang pada novel 9 Matahari menceritakan diterimanya Matari Anas di Universitas Panitan, Kota Bandung program ekstensi jurusan IImu Komunikasi. Matari Anas sadar bahwa dalam memenuhi kebutuhan hidupnya, ia tidak bisa mengandalkan sepenuhnya dari keluarga. Dengan kondisi seperti ini, ia berusaha untuk mencari pekerjaan dalam memenuhi kebutuhannya sehari-hari. Akhirnya, Matari Anas di terima menjadi penyiar di radio Qyu FM, salah satu radio di Kota Bandung. Lain halnya dengan tahap berkembangnya konflik pada novel 9 Summers 10 Autumns terjadi sejak tokoh Aku (Iwan) tiba di Bogor. la merasa terdampar di dermaga asing. la merasa rindu dengan keluarganya di Batu. Dan hanya lewat telepon kerinduan itu sedikit terobati. Isak tangis selalu mengakhiri perbincangan dengan ibunya. Saat masamasa kuliah di Bogor Iwan harus pintar-pintar mengatur keuangannya. Kelincahan mengatur uang sangat diperlukan pada saat itu. Dengan keprihatinan dan kesederhanaan yang luar biasa Iwan berusaha bertahan dan berjuang untuk dapat hidup di Bogor dan menyelesaikan kuliah.

\section{Tahap Klimaks (Climax)}

Tahap ini terjadi ketika pengarang novel 9 Matahari menceritakan permasalahan biaya kuliah. Saat memasuki semester lima Matari Anas tidak bisa mengikuti Ujian Akhir 
Semester (UTS) karena belum membayar uang semester. Berbagai cara dilakukan sampai berhutang kepada temannya yang bernama Mirna. Di tengah kesibukannya, Matari tak jarang untuk menyempatkan pulang kerumahnya. la mendapatkan kondisi keluarganya yang tidak berubah. Ayahnya masih tetap mengecam niat kuliahnya itu. Dengan sifat Ayahnya yang keras, tak jarang terjadi perdebatan dan sering terdengar bentakan atau suara keras yang dikeluarkan Ayah kepada mereka. Puncak permasalahan pada novel 9 Summers 10 Autumns hampir sama dengan novel 9 Matahari yaitu permasalahan biaya kuliah. Pada saat memasuki tingkat dua, Iwan harus membayar uang kuliah dan uang kost bersamaan dengan Mbak Inan yang harus membayar uang kuliah. Berbagai macam cara dilakukan oleh seluruh keluarga untuk mencukupi kebutuhan tersebut dan akhirnya Bapak pun harus meminjam uang kepada saudaranya untuk membayar keperluan itu.

\section{Tahap Penyelesaian (Denouement)}

Tahap ini merupakan penyelesaian suatu konflik. Dalam novel 9 Matahari pengarang menceritakan sikap dari Bapak Mantari yang akhirnya mendukung usahanya untuk menjadi seorang sarjana setelah melihat usaha anaknya yang pantang menyerah. Pada akhirnya Mantari pun lulus dengan nilai $A$, meskipun ia menghabiskan 6 tahun untuk mencapai sarjana (S1) dengan masa cuti 3 semester. Pada novel 9 Summers 10 Autumns tahap ini hampir sama dengan novel 9 Matahari yaitu menceritakan Iwan berhasil menyelesaikan kuliahnya. Setelah melalui berbagai macam rintangan dan dengan perjuangan yang luar biasa sebuah kemenangan yang indah. Akhirnya hari itu tiba, salah satu hari yang paling indah dan menyentuh dalam hidup Iwan. Bahkan ia berhasil menjadi wisudawan terbaik fakultas MIPA dengan IPK 3,52.

Temuan kedua yaitu perbandingan latar belakang pengarang yang terdapat pada novel 9 Matahari karya Adenita dengan novel 9 Summers 10 Autumns karya Iwan Setyawan Latar belakang pengarang merupakan bagian dari unsur ekstrinsik dalam novel. Latar belakang pengarang adalah faktor-faktor dari dalam pengarang itu sendiri yang memengaruhi atau memotivasi pengarang dalam menulis sebuah karya sastra. Latar belakang pengarang ini menyangkut asal daerah atau suku bangsa, jenis kelamin, pendidikan, pekerjaan, agama, dan ideology pengarang. Unsur-unsur ini sedikit banyak akan berpengaruh pada isi novelnya. Misalnya, novel yang dikarang orang Padang akan berbeda dengan novel yang dibuat oleh orang Sunda, orang Inggris, atau orang Arab. Menurut Wellek dan Werren (dalam Nurgiyantoro, 2010: 23), terdapat unsur ekstrinsik yang tergolong latar belakang pengarang, yaitu (1) biografi pengarang, biografi adalah bahwa karya seseorang pengarang tidak akan lepas dari pengarangnya. Jika seorang menulis beberapa karya dalam hidupnya, maka karya-karya itu dapat ditelusuri melalui biografinya. Hal-hal yang mencakup biografi adalah latar belakang keluarga, pendidikan, dan profesi pengarang; (2) faktor psikologis (proses kreatif), bagi seorang penulis cerita rekaan, hal terpenting dalam faktor psikologis adalah penciptaan tokoh-tokoh dan wataknya. Tokoh-tokoh dan wataknya harus sedemikian hidup sehingga meyakinkan pembaca akan kebenaran cerita; (3) faktor sosiologis, dalam cerita rekaan diuraikan berdasarkan asumsi bahwa ceita rekaan adalah potret/cermin kehidupan masyrakat. Kehidupan sosial adalah problem hubungan sosial, adat-istiadat, dan faktor historis; dan (4) faktor filsafat, dalam karya sastra adalah bahwa pengarang menganut aliran filsafat tertentu dalam berkarya seni serta ideologi yang dianut oleh pengarang tersebut sehingga pembaca akan lebih mudah menangkap makna karya sastra tersebut (Waluyo, 1994:64-65). Di bawah ini akan dipaparkan latar belakang pengarang dari novel 9 Matahari karya Adenita dan novel 9 Summers 10 Autumns karya Iwan Setyawan.

\section{Biografi Pengarang}

Hal-hal yang mencakup biografi adalah latar belakang keluarga, pendidikan, dan profesi pengarang. Dalam novel 9 Matahari, tokoh Matari Anas diceritakan berasal dari keluarga yang kurang mampu. Meskipun dengan keadaan ekonomi yang seperti itu, Matari Anas mampu menjadikan dirinya seorang sarjana. Untuk memenuhi kebutuhan saat menempuh pendidikan disalah satu universitas di kota Bandung, ia menjadi penyiar radio disalah satu radio di kota Bandung. Latar belakang keluarga, pendidikan, dan profesi hampir sama dengan kehidupan pengarang. Adenita berasal dari keluarga yang sederhana dan ia merupakan seorang sarjana sempat berkuliah di universitas yang berada di kota Bandung. Semasa kuliah ia pernah menjadi penyiar di Radio OZ FM Bandung, News writer di Trijaya FM Bandung, dan terakhir di radio otomotif 
dan olahraga, Auto Radio FM (Adenita, 2008: 359).

Pada novel 9 Summers 10 Autumns hampir sama dengan novel 9 Matahari yaitu tokoh Aku (Iwan) berasal dari keluarga yang sangat sederhana. Hidup dalam kondisi kekurangan, tidak mematahkan semangatnya untuk menggapai cita-cita. Untuk memenuhi kebutuhannya tokoh Aku memberikan les privat murid SD dan SMP di salah satu sekolah di kota Malang. Tokoh Aku menempuh pendidikan di IPB Bogor. Setelah ia menyelesaikan pendidikan sarjana, diceritakan tokoh Aku bekerja selama dua tahun di Nielsen Jakarta. Selesai bekerja di Nielsen, tokoh Aku bekerja sebagai data analis di Danareksa Research Institute dan selanjutnya merambah karier ke New York. Latar belakang keluarga, pendidikan, dan profesi sama dengan kehidupan pengarang. Iwan Setyawan berasal dari keluarga yang sederhana. la merupakan lulusan dari Fakultas MIPA IPB dari Jurusan Statistika. Iwan Setyawan pernah bekerja di Nielsen dan Danareksa Research Institute. la selanjutnya merambah karier di New York City selama 10 tahun (Setyawan, 2011).

\section{Faktor Psikologis (Proses Kreatif)}

Dalam novel 9 Matahari tokoh yang menggambarkan pengarang (Adenita) ialah Matari Anas. Dalam novel, diceritakan tokoh Matari Anas merupakan perempuan yang mempunyai semangat, pantang menyerah, tegar, dan kuat menghadapi segala masalah dalam hidupnya. Hampir sama dengan watak pengarang novel (Adenita) yang mempunyai semangat dan pantang menyerah. Hal itu dibuktikan melalui pengakuan sebenarnya ia merupakan orang pemalu, tapi suka menjajal diri untuk berkompetisi (Adenita, 2008: 258). Pada novel 9 Summers 10 Autumns hampir sama dengan novel 9 Matahari. Dalam novel 9 Summers 10 Autumns tokoh yang menggambarkan pengarang (Iwan Setyawan) ialah Aku. Dalam novel tokoh Aku ini merupakan seorang yang pintar, pantang menyerah, tekun, dan pekerja keras. Watak dari tokoh Aku ini sama dengan pengarang novel ini. Hal itu dibuktikan dengan Iwan merupakan lulusan terbaik Fakultas MIPA IPB tahun 1997. la juga bekerja di beberapa tempat, seperti Nielsen dan Danareksa Research Institute serta merambah karier di New York City (Setyawan, 2011).

\section{Faktor Sosiologis (Kemasyarakatan)}

Dalam novel 9 Matahari, terdapat hubungan sosial di dalam ceritanya yang dilakukan oleh tokoh Matari Anas melalui sikap sadar hak dan kewajiban diri sendiri dan orang lain, patuh pada aturan-aturan sosial, serta menghargai karya dan prestasi orang lain. Sikap hak dan kewajiban diri sendiri dan orang lain, di tunjukan oleh Matari Anas dengan menerima pemberian haknya setelah bekerja. Sama halnya dengan kehidupan sosial pengarang novel ini yaitu Adenita, yang memiliki hak dan kewajiban diri sendiri dengan menerima haknya setelah bekerja menjadi penyiar radio di Bandung. Pada novel 9 Summers 10 Autumns berbeda dengan novel 9 Matahari. Dalam novel 9 Summers 10 Autumns terdapat hubungan sosial di dalam cerita dilakukan oleh tokoh Aku yang sebenarnya suka menyendiri, namun karena keinginannya untuk bisa bergabung dengan rekan kerjanya, ia berusaha memberanikan diri untuk bergabung. Mereka pergi makan bersama, berdiskusi, sampai akhirnya tumbuh ikatan melebihi rekan kerja. Hingga tokoh Aku merasakan memiliki keluarga baru. Sama halnya dengan kehidupan sosial pengarang novel ini yaitu Iwan Setyawan, yang sering bergabung dengan rekan kerjanya saat bekerja di Jakarta maupun di New York City dan ia merasakan memiliki keluarga baru saat jauh dari keluarganya.

Berdasarkan hasil penelitian yang telah diuraikan, diperoleh beberapa temuan bermakna. Temuan itu dijabarkan sebagai berikut. Temuan petama tentang perbandingan alur yang terdapat pada novel 9 Matahari karya Adenita dengan novel 9 Summers 10 Autumns karya Iwan Setyawan. Dalam kedua novel ditemukan lima tahap alur yaitu tahap penyituasian (situation), tahap pemunculan konflik (generating circumstances), tahap peningkatan konflik (rising action), tahap klimaks (climax), tahap penyelesaian (denouement).

Secara umum, cerita novel 9 Matahari karya Adenita dan novel 9 Summers 10 Autumns karya Iwan Setyawan memiliki persamaan yaitu pendidikan di tengah himpitan ekonomi. Kedua novel ini banyak menceritakan perjuangan seorang tokoh untuk mencapai cita-cita menjadi sarjana dan sukses. Cerita novel ini menyadarkan pembaca bahwa pendidikan itu penting dalam kehidupan, karena membekali diri dengan ilmu dapat memudahkan kita menjalani kehidupan yang baik dan layak. Selain itu, cerita novel ini juga menginspirasi orang yang memiliki masalah ekonomi dalam menjalankan pendidikan agar semangat, pantang 
menyerah, dan kerja keras untuk dapat merubah hidupnya menjadi lebih baik.

Meskipun kisah novel 9 Matahari dan novel 9 Summers 10 Autumns hampir sama, tahap alur cerita pada kedua novel itu memiliki persamaan maupun perbedaan. Riyadi (1993: 57) mengemukakan bahwa alur atau plot adalah urutan peristiwa. Proses terjadinya alur pada dasarnya direncanakan oleh pencerita. Alur dapat dikatagorikan ke dalam beberapa jenis, yaitu alur lurus (progresif), alur sorot balik (flashback), dan alur campuran. Dalam kedua novel itu menggunakan alur lurus (progresif) yang memiliki lima tahapan. Tasrif (dalam Nurgiyantoro, 2009: 149), tahapan alur lurus dapat dibedakan menjadi lima bagian, yaitu a) tahap penyituasian (situation), berisi pelukisan dan pengenalan situasi latar dan tokoh-tokoh cerita, b) tahap generating circumstances, yaitu tahap pemunculan konflik, c) tahap peningkatan konflik (rising action), yaitu tahap konflik yang telah muncul pada tahap sebelumnya semakin berkembang dan dikembangkan kadar intensitasnya, d) tahap klimaks (climax), yaitu pertentangan yang terjadi, yang diakui dan atau ditimpakan kepada para tokoh cerita mencapai titik intensitas puncak, e) tahap denouement, yaitu tahap penyelesaian, konflik yang telah mencapai klimaks diberi penyelesaian, ketegangan dikendorkan.

Perbedaan tahapan alur dalam novel 9 Matahari dan 9 Summers 10 Autumns telihat pada tahap penyituasian (situation) dan tahap peningkatan konflik (rising action). Perbedaan tersebut sangat jelas dirasakan karena awal cerita pada tahap penyituasian, novel 9 Matahari langsung mengarah pada kondisi ekonomi keluarga tokoh sedangkan novel 9 Summers 10 Autumns hanya memaparkan latar tempat dan peristiwa yang dialami tokoh di tempat tersebut. Dalam kedua novel ini, tahap peningkatan konflik juga terdapat perbedaan, yaitu novel 9 Matahari menceritakan tentang permasalahan ekonomi di rantauan sedangkan novel 9 Summers 10 Autumns menceritakan kerinduan kepada keluarganya saat di rantauan. Hal tersebut sangat terlihat perbedaan perjuangan hidup kedua tokoh untuk menjadi seorang sarjana dan sukses.

Selain perbedaan, adapun persamaan tahap alur yang terlihat dalam novel 9 Matahari dan novel 9 Summers 10 Autumns, yaitu pada tahap pemunculan konflik, tahap klimaks, dan tahap penyelesaian. Selama menempuh pendidikan, pasti ada banyak halangan maupun kendala yang dialami oleh seseorang. Dalam cerita kedua novel itu, memiliki halangan maupun kendala yang sama dialami oleh tokoh-tokohnya seperti tidak lulus UMPTN disuatu universitas, permasalahan pembiayaan kuliah, dan sampai akhirnya kedua tokoh mampu menyelesaikan pendidikan sarjananya, menjadi orang sukses, serta membanggakan kedua orangtuanya.

Selain membandingkan alur, peneliti juga membandingkan latar belakang pengarang yang terdapat pada novel 9 Matahari karya Adenita dengan novel 9 Summers 10 Autumns karya Iwan Setyawan. Latar belakang pengarang merupakan bagian dari unsur ekstrinsik dalam novel. Latar belakang pengarang adalah faktor-faktor dari dalam pengarang itu sendiri yang memengaruhi atau memotivasi pengarang dalam menulis sebuah karya sastra. Menurut Wellek dan Werren (dalam Nurgiyantoro, 2010: 23), terdapat unsur ekstrinsik yang tergolong latar belakang pengarang, yaitu (1) biografi pengarang, (2) faktor psikologis (proses kreatif), (3) faktor sosiologis, dan (4) faktor filsafat. Dalam kedua novel itu hanya terdapat tiga latar belakang pengarang, yaitu biografi pengarang, faktor psikologis, dan faktor sosiologis.

Cerita dalam novel 9 Matahari dan novel 9 Summers 10 Autumns umumnya mengambil kisah yang telah dialami oleh pengarangnya sendiri yaitu Adenita dan Iwan Setyawan. Biografi pengarang adalah bahwa karya seseorang pengarang tidak akan lepas dari pengarangnya. Hal-hal yang mencakup biografi adalah latar belakang keluarga, pendidikan, dan profesi pengarang. Biografi pengarang dalam novel 9 Matahari memaparkan tokoh Matari Anas dari keluarga berkecukupan menempuh pendidikan di universitas kota Bandung dan pernah menjadi penyiar radio di Bandung untuk memenuhi kebutuhannya selama kuliah. Sama halnya dengan kehidupan pengarang yaitu Adenita berasal dari keluarga sederhana, menempuh pendidikan di kota Bandung, dan semasa kuliah Adenita bekerja menjadi penyiar radio di Radio OZ FM, news writer di Trijaya FM Bandung, dan terakhir di radio otomitif dan olahraga Auto Radio FM (Adenita: 2008: 359).

Kehidupan Iwan Setyawan juga memiliki persamaan dengan yang diceritakan dalam novel 9 Summers 10 Autumns. Iwan Setyawan berasal dari keluarga yang sederhana, ia menempuh pendidikan di Fakultas MIPA IPB Jurusan Statistika, dan pernah bekerja di Nielsen, Danareksa Research Institute, serta merambah karier di New York City (Setyawan, 2011). Dalam novel tokoh Aku diceritakan berasal dari keluarga 
yang sederhana, pendidikan maupun perkejaan dituliskan sama dengan di kehidupan nyata pengarang.

Faktor psikologis (proses kreatif) dalam cerita novel 9 Matahari dan novel 9 Summers 10 Autumns hampir sama dengan psikologis pengarangnya. Matari Anas dalam novel 9 Matahari memiliki semangat, pantang menyerah, tegar dan kuat menghadapi masalah. Sedangkan tokoh Aku dalam novel novel 9 Summers 10 Autumns merupakan seorang yang pintar, pantang menyerah, tekun, dan pekerja keras. Kedua tokoh dalam kedua novel tersebut sangat jelas menggambarkan watak dari pengarang yaitu Adenita dan Iwan Setyawan.

Faktor sosiologis biasanya pengarang membuat berdasarkan kehidupan sosial atau masyarakat. Kehidupan sosial adalah problem hubungan sosial, adat-istiadat, dan faktor historis. Dalam novel 9 Matahari sikap sosial yang ditujukkan Adenita dalam cerita ialah sikap hak kewajiban diri sendiri dan orang lain. Berbeda dengan sikap sosial yang disampaikan dalam novel 9 Summers 10 Autumns, Iwan Setyawan menunjukkan hubungan sosial dengan orang disekitarnya.

\section{PENUTUP}

Berdasarkan temuan penelitian yang telah dipaparkan pada hasil dan pembahasan, maka penulis dapat menarik beberapa simpulan sebagai berikut.

Alur novel 9 Matahari karya Adenita dan novel 9 Summers 10 Autumns karya Iwan Setyawan dibedakan menjadi lima bagian, yaitu tahap penyituasian (situation), tahap pemunculan konflik (generating circumstances), tahap peningkatan konflik (rising action), tahap klimaks (climax), dan tahap penyelesaian (denouement). Dari kelima tahap tersebut, perbedaan antara kedua novel itu terletak pada tahap penyituasian (situation) dan tahap peningkatan konflik (rising action), sedangkan persamaan terletak pada tahap pemunculan konflik (generating circumstances), tahap klimaks (climax), dan tahap penyelesaian (denouement).

$$
\text { Latar belakang pengarang }
$$
digolongkan menjadi empat, yaitu biografi pengarang, faktor psikologis (proses kreatif), faktor sosiologis, dan faktor filsafat. Dalam novel 9 Matahari karya Adenita dan novel 9 Summers 10 Autumns karya Iwan Setyawan terdapat tiga golongan latar belakang pengarang, yakni biografi pengarang, faktor psikologis (proses kreatif), dan faktor sosiologis. Dari ketiga golongan tersebut, perbedaan antara kedua novel terletak pada faktor sosiologi, sedangkan persamaan terletak pada biografi pengarang dan faktor psikologis (proses kreatif).

Berdasarkan temuan-temuan dalam penelitian ini, penulis dapat menyampaikan beberapa saran, yaitu (1) bagi pemerhati sastra (peminat sastra), disarankan agar membaca dan memahami khususnya alur dan latar belakang pengarang novel 9 Matahari karya Adenita dengan novel 9 Summers 10 Autumns karya Iwan Setyawan karena sangat inspiratif, penuh motivasi, dan nilai-nilai yang dapat diaplikasikan dan sangat berguna bagi masa depan ketika berada di masyarakat umum, dan (2) bagi peneliti lain, disarankan agar peneliti selanjutnya dapat melakukan penelitian kembali baik yang berhubungan dengan penelitian ini, maupun berhubungan dengan masalah lain menggunakan novel 9 Matahari karya Adenita atau novel 9 Summers 10 Autumns karya Iwan Setyawan karena kedua novel ini sangat inspiratif dan memotivasi dalam menjalankan pendidikan.

\section{DAFTAR PUSTAKA}

Adenita. 2008. 9 Matahari. Jakarta: PT Grasindo Anggota Ikapi.

Akbar, Syahrizal, Retno Winarni, Andayani. 2013. Kajian Sosiologi Sastra dan Nilai Pendidikan dalam Novel "Tuan Guru" Karya Salman Fariz. Jurnal Pendidikan Bahasa dan Sastra Vol. 1 No. 1 Hal. 54-68. Tersedia Pada: https://digilib.uns.ac.id/dokumen/detail/ 29547/Kajian-Sosiologi-Sastra-DanNilai-Pendidikan-Dalam-Novel-TuanGuru-Karya-Salman-Faris.

Arikunto. 2003. Manajemen Penelitian. Jakarta: Rineka Cipta.

Azizah, Aida, Leli Nisfi Setiana. 2016. Karakter Tokoh dalam Novel Langit Mekah Berkabut Merah Karya Geidurrahman Al-Mishry Berbasis Nilai-Nilai Karakter Religius dan Implikasinya dalam Pembelajaran Sastra di Madrasah Aliyah. Jurnal Refleksi Edukatika 7 (1) Hal. 78-83. Tersedia Pada: http://jurnal.umk.ac.id/index.php/RE.

Hermawan, Asep. 2015. Unsur Intrinsik Novel Sang Pemimpi Karya Andrea Hirata Sebagai Alternatif Bahan Ajar Membaca di SMP. Riksa Bahasa Volume 1, Nomor 2, Hal. 146-152. 
Tersedia

Pada:

https://ejournal.upi.edu/index.php/RBS

Ps/article/view/8755.

Istiqomah, Nuriana. Mukh.Doyin, dan Sumartini. 2014. Sikap Hidup Orang Jawa Dalam Novel Orang-Orang Proyek Karya Ahmad Tohari. Jurnal Sastra Indonesia Vol. 3 No. 1 Hal. 1-9. Tersedia Pada: http://journal.unnes.ac.id/sju/index.php /jsi.

Nurgiyantoro, Burhan. 2009. Teori Pengkajian Fiksi. Yogyakarta: Gadjah Mada University Press.

Nurgiyantoro, Burhan. 2010. Teori Pengkajian Fiksi. Yogyakarta: Gajah Mada University Press.

Riyadi, Slamet, Dkk. 1993. Cerita Anak-anak Dalam Sastra Jawa. Yogyakarta: Proyek Penelitian dan Pembinaan Bahasa dan Sastra Indonesia dan Daerah.

Setyawan, Iwan. 2011. 9 Summers 10 Autumns. Jakarta: PT Gramedia Pustaka Utama.

Suandi, I Nengah. 2008. Pengantar Metodelogi Penelitian Bahasa. Singaraja: Universitas Pendidikan Ganesha.

Sudjidman, Panuti. 1992. Memahami Cerita Rekaan. Jakarta: Pustaka Jaya.

Sugiyono. 2007. Metode Penelitian Pendidikan. Bandung: Alfabeta.

Waluyo, Herman. 1994. Pengkajian Cerita Fiksi. Surakarta: Sebelas Maret Universiy Press.

Wendra. 2014. Penulisan Karya IImiah. Singaraja: Universitas Pendidikan Ganesha.

Yanti, Citra Salda. 2015. Religiositas Islam dalam Novel Ratu yang Bersujud Karya Amrizal Mochamad Mahdavi. Jurnal Humanika No. 15, Vol. 3, Hal. 1-15. Tersedia Pada: http://ojs.uho.ac.id/index.php/HUMANI KA/article/view/585. 